REVISTA DE DERECHO UNED, núm. 6, 2010

\title{
EL CONSENTIMIENTO DE LA VÍCTIMA DE LA VIOLENCIA DE GÉNERO Y DOMÉSTICA Y SU INCIDENCIA EN EL DELITO DE QUEBRANTAMIENTO DE CONDENA Y DE MEDIDA CAUTELAR SEGÚN LA JURISPRUDENCIA DEL TRIBUNAL SUPREMO.
}

\author{
ANNA Ma SOLÉ RAMÓN \\ Doctoranda en la UNED
}

Resumen: En el presente artículo analizamos la jurisprudencia del TS en la que aborda la relevancia o irrelevancia del consentimiento de la víctima de violencia de género y/o doméstica en relación con el delito de quebrantamiento de condena y de medida cautelar en el que incurriría el agresor en caso de reconciliación entre ambos y/o reanudación de la convivencia; así como si cabe considerar dicho consentimiento como una causa de justificación.

Palabras clave: Quebrantamiento de condena; quebrantamiento de medida cautelas; consentimiento de la víctima; reconciliación víctima-agresor; reanudación de la convivencia; causa de justificación.

Summary: In this paper we analyze the Spanish Supreme Court jurisprudence regarding the relevance of the consent of the victim of domestic violence.

In the course of reconciliation between the perpetrator and victim, and resumption of cohabitation does the offender commits a crime of breach of sentence or a crime of breach of interim measure? We also analyzed whether this consent can be considered as a justification in relation to this crime. 
Important words: Breach of sentence, breach of interim measure, a justification, resumption of convincing, reconciliation between victim and aggressor.

Sumario: I. Introducción.-II. La STS de 26 de septiembre de 2005.-III. Objeciones.-IV. Cambio de postura doctrinal.-V. Conclusiones.-VI. Bibliografía.

\section{INTRODUCCIÓN}

Conforme al art. 57.2 del CP será obligatorio acordar siempre en sentencia como pena accesoria la prohibición de aproximación del art. 48.2 del CP respecto de los delitos relacionados con la violencia de género y de violencia doméstica. El único supuesto en el que se prevé como facultad del Juez el acordarlo o no es respecto de las faltas en el ámbito familiar del art. 620 del CP (amenazas, coacciones, injurias y vejaciones injustas).

Este régimen de imposición preceptiva ha dado lugar a numerosas críticas por parte de la doctrina, sobre todo en relación a los supuestos de reconciliación víctima-agresor y reanudación de la convivencia $y$, por tanto, en los supuestos de quebrantamiento de condena y quebrantamiento de medida cautelar. El artículo $468 \mathrm{CP}$ castiga con la pena de prisión de seis meses a un año a los que quebrantaren una pena de las contempladas en el artículo 48 del CP, o una medida cautelar o de seguridad de la misma naturaleza, que hayan sido impuestas en procesos criminales en los que el ofendido sea alguna de las personas a las que se refiere el artículo $173.2 \mathrm{CP}$.

Algún sector de la doctrina ha criticado el tratamiento no diferenciado en cuanto a las penas aplicables entre el quebrantamiento de la condena a una prohibición de aproximación y/o de comunicación por parte del agresor y el quebrantamiento de una medida cautelar de la misma naturaleza, bajo el argumento de que tienen una naturaleza jurídica distinta: el quebrantamiento de medida cautelar merecería una pena menos grave que el quebrantamiento de una condena ${ }^{1}$. Este mismo argumento es el que escogemos para afirmar que el consentimiento de la víctima a reanudar la convivencia debería tener un trato diferenciado si nos encontramos ante un quebrantamiento de medida cautelar, en la que dicho consentimiento debería

1 JIMÉNEZ DÍAZ, M. J.: «Algunas reflexiones sobre el quebrantamiento inducido o consentido», en La Ley Integral: un estudio multidisciplinar (M. ${ }^{a}$ José Jiménez Díaz, coordinadora). Ed. Dykinson; Madrid, 2009, p. 413. 
El CONSENTIMIENTO DE LA VÍctima DE LA VIOLENCIA DE GÉNERO...

excluir la antijuridicidad del hecho delictivo constitutivo de un delito de quebrantamiento del artículo $468 \mathrm{CP}$, de si nos encontramos ante un quebrantamiento de condena, en el que el consentimiento de la víctima debería considerarse irrelevante, encontrándonos ante un hecho típico y antijurídico.

\section{LA STS DE 26 DE SEPTIEMBRE DE 2005}

La doctrina del Tribunal Supremo ha sido incoherente en esta materia y ha dado lugar a cierta inseguridad jurídica. Así, hasta la Sentencia de fecha 26 de septiembre de 2005, estimó que el consentimiento de la víctima era irrelevante a los efectos de considerar que se ha producido el delito, tanto si nos encontrábamos ante un supuesto de quebrantamiento de medida cautelar como de pena de alejamiento ${ }^{2}$.

La Sentencia del Tribunal Supremo de fecha 26 de septiembre de 2005 (Sentencia n. ${ }^{\circ}$ 1156/2005. Ponente Sr. D. Joaquín Giménez García) supone un cambio de orientación en la línea seguida hasta ese momento. Esta sentencia, a pesar de afirmar la naturaleza delictiva del incumplimiento de las penas privativas de derechos y de que el cumplimiento de una pena no puede quedar al arbitrio del condenado, que las penas se imponen para ser cumplidas, lo mismo respecto de la medida de alejamiento como de la medida cautelar, matiza respecto de la pena o medida cautelar de prohibición de aproximación que la efectividad de la medida depende de la necesaria e imprescindible voluntad de la víctima - en cuya protección se acuerda- de mantener su vigencia siempre y en todo momento. Continúa la sentencia citada que hay que estimar que, en estos casos, la reanudación de la convivencia acredita la desaparición de las circunstancias que justificaron la medida de alejamiento o pena dictada por lo que ésta debe desaparecer y queda extinguida, sin perjuicio de que ante una nueva secuencia de violencia se pueda solicitar y obtener - en su caso- otra medida de alejamiento. ("...la decisión de la mujer de recibirle y reanudar la vida con él, acredita de forma fehaciente la innecesidad de protección, y por tanto supone de facto el decaimiento de la medida de forma definitiva, por lo que el plazo de duración de la medida fijado por la autoridad judicial, quedaría condicionado a la voluntad de aquélla»).

${ }^{2}$ Ver STS de 16 de mayo de 2003. 
Entendemos, siguiendo a un sector doctrinal, que esta sentencia viene a decirnos que en esta materia es importante la voluntad de la víctima, viniendo así a matizar la aplicación literal de la ley pero que «confunde el tratamiento de la medida cautelar y de la pena de alejamiento» ya que no cabe en un Estado de Derecho la disponibilidad de las penas impuestas en sentencia. Señala Jiménez Díaz ${ }^{3}$ que «unas veces el TS parece querer distinguir ambos supuestos y dejar claro que se trata de hipótesis diferentes que, por tanto, merecen un trato distinto, en tanto que otras los equipara».

El criterio recogido en esta sentencia del Tribunal Supremo ha sido seguido por diversos Juzgados de lo Penal y también por diversas Audiencias Provinciales con competencia en la materia, por entender que el Estado no puede intervenir cuando la víctima ha decidido que no precisa esta medida. Las soluciones ofrecidas van desde la consideración de que la conducta del agresor estaría afectada por un error de prohibición hasta la atipicidad de dicha conducta por afectar al dolo que exige la comisión del delito, la existencia de una situación de estado de necesidad, la falta de antijuridicidad de la conducta o la existencia de una eximente del art. 20.1 del Código Penal. Así podemos citar entre otras las siguientes sentencias:

SAP de Tarragona 6 de febrero de 2008: «... se trata de un delito doloso de manera que el incumplimiento de la pena ha de serlo de forma consciente y voluntaria, lo que excluirá, en consecuencia, los supuestos de encuentros puramente fortuitos o los producidos por fuerza mayor, aquellos en los que concurra algún tipo de causa de justificación, o de exclusión de la culpabilidad, así como cuando se demuestre la concurrencia de error de tipo o de prohibición en el obligado o incluso algún supuesto de delito provocado».

SAP de Cádiz de 21 de enero de 2003: La mencionada sentencia afirma que el consentimiento de la víctima no puede dejar indiferente al intérprete de la ley y que en virtud del principio de intervención mínima y de proporcionalidad la conducta de aproximación a la víctima, mediando éste, reconduciría el hecho al error de prohibición cuando el agresor crea que ya no tiene vigencia la prohibición de aproximación a la vista de dicho consentimiento de la víctima.

«... Así pues, creemos que no se prestó el consentimiento por quien aparentemente estaba legitimada al efecto para que el acusado pudiera vulnerar la orden de alejamiento. Pero lo que debemos realmente preguntarnos es si existía tal legitimación. En otras palabras, el problema

3 JIMÉNEZ DÍAZ, M. J.: ob. cit., p. 409. 
El CONSENTIMIENTO DE LA VÍctima DE LA VIOLENCIA DE GÉNERO...

es si el consentimiento de la persona objeto de protección por la orden de alejamiento, puede autorizar al imputado, obligado a su respeto, para que habitual o puntualmente la vulnere, y todo ello con alguna relevancia en el correspondiente tipo penal...».

«... Son elementos conformadores del citado delito los que, a continuación, se detallan:

1.-La existencia de una resolución judicial que imponga la medida cautelar al acusado.

2.-El conocimiento de dicha medida por parte del recurrente.

3.-El incumplimiento de la meritada medida por su parte,de forma consciente y voluntaria.

4.-En la notificación de la medida cautelar que se hizo al acusado se le advirtió de la responsabilidad en la que podía incurrir en el caso de su incumplimiento.

5.-La comisión del presente ilícito no requiere una reiteración en la infracción de la medida cautelar, significativa de una rebelde oposición a su cumplimiento, sino que su desobediencia ya supone, en sí misma, el quebrantamiento en aras a la protección de la víctima y a la efectividad y respeto que merecen las resoluciones judiciales cuya observancia, en modo alguno, debe quedar sometida a la voluntad del imputado.

6.-Y todo ello viene adobado con el carácter pluriofensivo del tipo analizado, que tiene que ver, primera y primordialmente, con la protección a las víctimas de los delitos previstos en el art. 57 del Código Penal (al que se refiere el art. 533, bis de la Ley de Enjuiciamiento Criminal), pero también con el respeto debido a las resoluciones judiciales y en especial con las garantías en la ejecución no ya de las penas, sino tambiénde medidas cautelares tan puntualmente necesarias y precisas como la que motiva la formación de esta causa.

Corolario de cuanto decimos es la afirmación de la inexistencia de elemento alguno en el tipo objetivo del delito imputado que tenga que ver con la ausencia de consentimiento de la víctima, esto es, que estando presente éste se excluya la comisión del tipo. Y es que el delito de quebrantamiento de medida cautelar es de resultado cortado: acreditada la existencia de la medida de alejamiento y acreditado el incumplimiento, se han rellenado las previsiones del tipo, sin que quepan argumentaciones acerca de extremos tales como la existencia de un perdón o reconciliación que haga innecesaria la medida o la presencia de autorizaciones puntuales de la víctima para que el imputado pueda vulnerar la medida y visitar a aquella o a la descendencia común. A falta de men- 
ción expresa en la Ley que justifique la posición contraria, pensamos que conferir relevancia típica al consentimiento —o más bien a su faltapondría en manos de la víctima una potente arma que podría utilizar caprichosamente en términos no admisibles por el Ordenamiento, pero que a su vez-y en su perjuicio la pondrían en el ojo de mira de toda suerte de coacciones y presiones del obligado a respetarla para que quedara sin efecto lo acordado, que son precisamente lo que la ley trata de repelar con la medida de alejamiento.

Con todo, que medie tal consentimiento no puede dejar indiferente al intérprete. Distinta valoración merece la conducta del que conscientemente vulnera una orden de alejamiento, que la de aquél que, en un cierto ambiente de relajación en la exigencia de su cumplimiento, recibe la autorización libre y expresa de la víctima para no respetarla, aun sin que se hubiera modificado judicialmente la medida. El respeto al principio de intervención mínima o la apelación a criterios de proporcionalidad sugieren que la última conducta sea reconducida al error de prohibición cuando se pueda considerar que el obligado al respeto de la orden de alejamiento crea que ya no tiene vigencia ante el consentimiento de la víctima. Y ello con las consecuencias exculpatorias o atenuatorias del art. 14.3 del Código Penal, según fuera invencible o vencible el error padecido por el imputado».

SAP de Vizcaya de 28 de diciembre de 2007: Esta sentencia parte de la premisa de que la reanudación de la convivencia acredita por sí misma la desaparición de las circunstancias que justificaron la medida de alejamiento, produciendo su «decaimiento», considerando la conducta del agresor que incumple la prohibición de aproximación típica pero antijurídica.

"... Así las cosas, contándose con ese precedente y sin que se haya sentado por la Sala ninguna postura previa o criterio interpretativo en contra, no se pueden ignorar las significativas circunstancias del supuesto enjuiciado que, sin duda, permiten afirmar que estamos ante un caso límite. El consentimiento es libre, voluntario y pleno, no pudiendo ofrecer una expresión más nítida. Víctima y acusado acordaron, como la propia sentencia afirma en su relato de hechos probados, la reanudación de la convivencia, sin que existan motivos para pensar en que no se hubiera producido libremente y sin que consten nuevos episodios de violencia. En el transcurso de esa nueva convivencia se produjeron los dos episodios en los que ambos fueron vistos.

El Tribunal Supremo no discute en su resolución la naturaleza indisponible de la sanción penal. Afirma que es "claro que la vigencia o anulación de la medida no puede quedar al arbitrio de aquella persona 
El CONSENTIMIENTO DE LA VÍctima DE LA VIOLENCIA DE GÉNERO...

en cuya protección se otorga" y se refiere al principio de seguridad jurídica y a la efectividad del pronunciamiento judicial, más aún partiendo de estas premisas, abre la puerta en la interpretación del precepto al "respeto al marco inviolable de su decisión libremente autodeterminada", por parte de la víctima, de reanudar la convivencia: "esta es la especificidad de esta medida/pena dado el específico escenario en el que desarrolla su eficacia", señala finalmente.

Es decir, constatado que esa voluntad no está viciada o condicionada, se trata de un consentimiento relevante que "acredita de forma fehaciente la innecesariedad de la de protección y por tanto supone el decaimiento de la medida". Lo contrario llevaría a la consideración de la víctima como coautora por cooperación necesaria, "lo que produciría unos efectos tan perversos que no es necesario razonar, al suponer una intromisión del sistema penal intolerable en la privacidad de la pareja, cuyo derecho más relevante es el derecho a 'vivir juntos', como recuerdan las SSTEDH de 24 de marzo de 1988 y de 9 de junio de 1998, entre otras".

Sobre al carácter indisponible de la sanción penal, y sobre la existencia de un bien jurídico distinto de la protección de la integridad de la víctima, el Tribunal Supremo estima en esta sentencia, en definitiva, que ha de prevalecer el derecho de la pareja a la reanudación de la convivencia, ejercido el cual en condiciones de plena libertad, el acercamiento pierde todo atisbo de antijuridicidad y la sanción penal todo su sentido.

La Sala comparte este criterio, estimando que sitúa la cuestión donde corresponde, en el plano de la antijuridicidad y no en el más inseguro y resbaladizo de la culpabilidad. No se trata de que el acusado actuara en la creencia de obrar de modo lícito o de que la medida no estaba vigente, sino, simplemente, de que, como dice el Tribunal Supremo, "la reanudación de la convivencia acredita la desaparición de las circunstancias que justificaron la medida de alejamiento", produciendo su «decaimiento» a los efectos que nos ocupan.

Procede, pues, la estimación del recurso interpuesto acordando la absolución del apelante por el delito de quebrantamiento de condena».

SAP de Tarragona de 4 de febrero de 2008: Según la AP queda descartada en el caso concreto la concurrencia de una causa de justificación basada en el ejercicio del derecho fundamental a la intimidad de la pareja consistente en la reanudación de la convivencia, por lo que el acusado es condenado por el delito de quebrantamiento de condena. 
"... En modo alguno queda acreditado que en el momento de los hechos el acusado y la "favorecida" por la medida hubieran reanudado la convivencia, con lo que no cabe apreciar conflicto alguno con el derecho fundamental a la intimidad de la pareja... Acreditado el elemento objetivo del tipo penal, y descartada la concurrencia de una causa de justificación basada en el ejercicio del derecho fundamental a la intimidad familiar (artículo $8 \mathrm{CEDH}$ ), el elemento subjetivo del tipo penal (conocimiento y voluntad de llevar a cabo la acción que vulnera la condena) cabe inferirlo de la propia presencia del acusado en las inmediacionesde la vivienda... La motivación que pudiera perseguir el sujeto cae fuera del tipo penal. Acreditado el conocimiento de la medida de alejamiento y acreditado el incumplimiento voluntario se colman las exigencias del tipo, debiendo en otro caso el acusado demostrar, por ejemplo, la concurrencia de una causa de justificación, o de exclusión de la culpabilidad, concurrencia de error, caso fortuito, fuerza mayor, etc., resultando indiferente que su intención fuera perfectamente lícita, o que no se haya producido el efecto dañoso para la víctima que la decisión judicial pretende evitar; de manera que no puede confundirse lo que es la motivación de una conducta, que no forma parte del tipo y resulta indiferente para el Derecho Penal en la mayor parte de las ocasiones, con el elemento subjetivo del delito que queda integrado con el conocimiento de la resolución y la conciencia del incumplimiento, a pesar de la cual el sujeto actua quebrantando la prohibición.

Tampoco podemos compartir el argumento que emplea el Juzgador relativo a que no consta si ella le propuso o indujo al acusado a que acudiera a Tortosa, máxime teniendo en cuenta que aquella retiró la denuncia después de la detención.

Nos encontramos, en primer lugar, ante un delito perseguible de oficio, que no precisa la interposición de denuncia por parte del "favorecido" por la medida. En segundo lugar, el hecho de que no conste acreditado que ella le propusiera o incitase a quebrantarla orden - ni siquiera hay atisbo de ello- precisamente nada vendría a demostrar sobre la supuesta falta de concurrencia del elemento subjetivo de la infracción, ni que nos encontremos ante un supuesto de delito provocado».

\section{OBJECIONES}

Las principales objeciones a la Sentencia del Tribunal Supremo de 26 de septiembre de 2005 residen que en ningún caso debe dejarse en manos de la víctima el decidir cuándo estamos ante un deli- 
El CONSENTIMIENTO DE LA VÍctima DE LA VIOLENCIA DE GÉNERO...

to de quebrantamiento de condena y cuándo no; cosa que ocurriría si, por reanudación de la convivencia y por renuncia a la pena de alejamiento acordada en sentencia dejásemos de estar ante un incumplimiento por parte del agresor de la pena de alejamiento. La vigencia o anulación de la pena no puede quedar al arbitrio de aquella persona en cuya protección se otorga, porque ello la convierte en árbitro de una decisión que no sólo le afecta a ella, sino también a la persona de quien se debe proteger. Ello conlleva una absoluta falta de seguridad jurídica para la otra persona, que prácticamente podría aparecer como autor del quebrantamiento según la exclusiva voluntad de la protegida, además de que ello supondría dejar la efectividad del pronunciamiento judicial a la decisión de un particular. La pena de alejamiento impuesta en sentencia es indisponible por la víctima. En todo caso, corresponde al órgano judicial encargado de la ejecución de la sentencia decidir si la pena debe ser cumplida o no.

En este sentido, la Circular 2/2004 de la Fiscalía General del Estado señala que «en los casos de reconciliación sobrevenida y de deseo de reanudar la convivencia o incluso supuestos de voluntad de continuar una convivencia en ningún momento interrumpida y debidamente ponderadas las circunstancias concurrentes, los Srs. Fiscales podrán informar favorablemente o promover de oficio peticiones de indulto parcial en relación con la pena de prohibición de aproximación, solicitando simultáneamente la suspensión de la ejecución de la misma conforme al art. 4.4 del CP, con el fin de evitar la a todas luces anómala situación que podría derivarse de una separación forzosa imperativa y contraria a la voluntad de los aparentes beneficiarios de la medida de protección $»^{4}$.

Cerezo Mir afirma que el consentimiento sólo puede eximir de responsabilidad penal en los delitos en los que el portador del bien jurídico protegido es un individuo, por lo que no puede eximir de responsabilidad penal en los delitos en que se protegen bienes jurídicos supraindividuales, es decir, cuyo portador sea la sociedad o el Estado $^{5}$. Por otra parte, Mir Puig entiende que la conformidad del afectado eximirá de responsabilidad penal cuando ello se desprenda del

${ }^{4}$ Circular de la Fiscalía General del Estado 2/2004.

VARGAS, A.: «El llamado quebrantamiento consentido y los nuevos instrumentos de valoración del riesgo». El Derecho. Revista de Jurisprudencia. Año III-Núm. 1, diciembre 2007, p. 2.

Auto de 29 de junio de 2005 del Juzgado de lo Penal n. 20 de Madrid. Cuestión de inconstitucionalidad del art. 57.2 del CP ante el Tribunal Constitucional, p. 1.

5 CEREZO MIR, J.: Curso de Derecho Penal Español, Parte General. Tomo II, sexta edición. Ed. Tecnos; Madrid, 2004, p. 326. 
tipo legal del delito respectivo o algún precepto le conceda expresamente eficacia justificante y también cuando el consentimiento pueda verse como «el libre desarrollo de la personalidad» tutelado en el art. 10.1 de la CE. Nada de ello sucederá en los delitos contra la colectividad, puesto que en ellos se protegen bienes independientes de la voluntad de un individuo, aunque supongan que la acción recae sobre una persona concreta ${ }^{6}$. Ello es perfectamente aplicable al delito de quebrantamiento de condena y de medida cautelar que se configura como un delito contra la Administración de Justicia.

En relación al quebrantamiento de medida cautelar, y siguiendo a Muñoz Conde, entendemos que hay algunos tipos penales específicos en los que se hace referencia expresa o tácita al consentimiento de la víctima (delito de allanamiento de morada, delitos de agresión sexual). En estos casos, dicho consentimiento se configura como una causa de exclusión de la tipicidad. Sin embargo, tal y como señala este autor, hay casos en los que el consentimiento no excluye directamente la tipicidad sino que puede excluir la antijuricidad, es decir, justificar una conducta que sigue siendo típica, siendo sus requisitos: a) que quede claramente manifestado, ya sea de forma expresa o de forma tácita; b) que el consentimiento sea una facultad reconocida por el ordenamiento jurídico a una persona para disponer válidamente de determinados bienes jurídicos; c) capacidad para disponer, lo cual exige unas facultades intelectuales para comprender el alcance y significación de sus actos por parte de quien consiente; d) ausencia de vicios, ya que cualquier vicio esencial de la voluntad del que consiente (error, coacción, violencia, engaño, etc.) invalida el consentimiento, y e) el consentimiento ha de ser dado antes de la comisión del hecho y ha de ser conocido por quien actúa a su amparo ${ }^{7}$.

Observamos que de todos estos requisitos, en el caso que nos ocupa, el ordenamiento jurídico español no reconoce - de momento- a la víctima de los delitos de violencia de género o doméstica la facultad de disponer válidamente del bien jurídico protegido por el delito de quebrantamiento de condena o medida cautelar que, en este caso, no es un bien jurídico individual y propio, sino colectivo, aunque con algunos matices a tener en cuenta.

Siguiendo la argumentación de Muñoz Conde, entendemos que el consentimiento de la víctima en el delito de quebrantamiento de me-

${ }^{6}$ MIR PUIG, S.: Derecho Penal, Parte General. Séptima edición. Ed. Reppertor; Barcelona, 2004.

7 MUÑOZ CONDE, F. y GARCÍA ARAN, M.: Derecho Penal. Parte general. Ed. Tirant lo Blanc; Valencia, 2004, pp. 344-346. 
dida cautelar no excluye la tipicidad del hecho sino la antijuricidad del mismo: estamos ante un supuesto que cae dentro del tipo del delito de quebrantamiento del artículo $468 \mathrm{CP}$ y que, por tanto, es típico. Sin embargo no es antijurídico, ya que el consentimiento de la víctima es relevante. Stratenwerth considera que el «principio de ponderación de bienes" puede fundamentar el consentimiento como causa de justificación en los delitos contra la sociedad y el Estado ${ }^{8}$. Noll se refiere a la "ponderación de intereses $»^{9}$. En el delito de quebrantamiento de medida cautelar se debe ponderar la libertad de la persona protegida y el libre desarrollo a su personalidad con la medida cautelar con el interés del Estado a que se cumplan las resoluciones judiciales. Si se concede prelación a la libertad individual y al libre desarrollo de la personalidad el consentimiento operará como causa de justificación en este delito. Y todo ello, habida cuenta que el tipo del artículo 468.2, segundo inciso CP no solo protege el interés del Estado en el cumplimiento de las resoluciones judiciales sino la seguridad de la persona a cuyo favor se acuerda una medida de alejamiento. De hecho, el precepto al que nos referimos castiga, tras la reforma introducida por la LO 1/2004, de 28 de diciembre, con un mayor reproche penal la conducta típica «cuando el ofendido sea alguna de las personas a que se refiere el artículo 173.2 CP», entendiendo que existe un mayor desvalor en el resultado.

Muñoz Conde acogiendo la postura de la STS de 26 de septiembre de 2005 señala que, en principio, no habrá quebrantamiento cuando la persona a favor de la cual se acordó la medida de alejamiento acepta que el sujeto al que se le impuso la medida cautelar o pena vuelva a acercarse o incluso a convivir con ella ${ }^{10}$. En el mismo sentido Silva Sánchez entiende que la postura acogida por la STS de 16 de mayo de 2003, según la cual el consentimiento de la propia víctima al quebrantamiento de las medidas cautelares de protección dictadas en interés suyo y para su protección o su conformidad con el quebrantamiento de las penas accesorias de naturaleza protectora impuestas al autor de tales delitos, no priva de relevancia típica a tales conductas de quebrantamiento al tratarse de medidas y penas no disponibles ni renunciables por parte de la víctima, ha sido superada por la STS de 26 de septiembre de 2005 según la cual «la decisión de la mujer de recibirle y reanudar la vida con él, acredita de forma fehaciente la inne-

${ }^{8}$ CEREZO MIR, J: Curso de Derecho Penal Español, Parte General. Tomo II, sexta edición. Ed. Tecnos; Madrid, 2004, p. 194.

${ }^{9}$ CEREZO MIR, J.: ídem, p. 334.

10 MUÑOZ CONDE, F.: Derecho Penal. Parte especial. Decimoséptima edición Ed. Tirant lo Blanc; Valencia, 2009, p. 883. 
cesidad de la protección y, por tanto, supone de facto el decaimiento de la medida de forma definitiva» ${ }^{11}$.

Como hemos vistos, mientras no se ha confirmado o se rectificado la solución ofrecida por el TS, las opiniones y posturas jurisprudenciales han sido variadas. Así, encontramos resoluciones que siguen la STS de 26 de septiembre de 2005 que otorgan relevancia al consentimiento de la víctima y absuelven al autor del quebrantamiento; otras que condenan al quebrantador y además extienden la responsabilidad penal a la víctima que induce o propicia el quebrantamiento, y otros pronunciamientos que distinguen entre quebrantamiento de pena y de medida cautelar, otorgando relevancia al consentimiento de la víctima en este último supuesto, que conlleva una absolución y condenando el quebrantamiento de pena, aunque igualmente exista dicho consentimiento ${ }^{12}$.

\section{CAMBIO DE POSTURA DOCTRINAL}

Con posterioridad a la Sentencia de 2005, el Tribunal Supremo ha tenido ocasión de volver a pronunciarse respecto del «quebrantamiento consentido». Así esta doctrina del Tribunal Supremo, que apuntaba a una nueva línea jurisprudencial con un importante vuelco de esos principios generales que se acaban de exponer, obligando a Jueces y Tribunales a revisar el criterio general sobre el delito de quebrantamiento de condena tratándose de condenas (o medias cautelares de protección) de ese tipo cuando el quebrantamiento se produce con el consentimiento y voluntad de la víctima protegida, no se ha visto consolidada, sino que ha sido rectificada con posterioridad. Así, en una primera Sentencia de fecha 20 de enero de 2006, el Alto Tribunal matizaba aquella doctrina a la que expresamente se refería declarando que «sólo un consentimiento firme y relevante por parte de la víctima puede ser apreciado a los efectos interesados por el recurrente y siempre desde la óptica propuesta de un error invencible...»; en una segunda Sentencia de fecha 19 de enero de 2007 declaraba que el consentimiento de la ofendida en el caso que examinaba «no podría eliminar la antijuridicidad del hecho, primero, porque el con-

11 SILVA SÁNCHEZ, J. M.(director) y Ragués i Vallés, R.(coordinador): Lecciones de Derecho Penal. Parte especial. Segunda edición. Ed. Atelier, Barcelona, 2009, pp. 360-361.

12 SAP Barcelona de 21 de febrero de 2007; SAP Barcelona de 28 de febrero de 2007, SAP Barcelona de 22 de marzo de 2007, SAP Madrid de 17 de mayo de 2007, entre otras. 
El CONSENTIMIENTO DE LA VÍctima DE LA VIOLENCIA DE GÉNERO...

sentimiento estaba condicionado o viciado por presiones de la familia...; y segundo, porque la vigencia del bien jurídico protegido no queda enervada o empañada por el consentimiento de la mujer, ya que es el principio de autoridad el que se ofende con el delito de quebrantamiento de medida. Cierto que tal medida se acuerda por razones de seguridad en beneficio de la mujer, para la protección de su vida e integridad corporal - que tampoco son bienes jurídicos disponibles por parte de aquélla-pero en cualquier caso no es el bien jurídico que protege el

precepto». Y aún con mayor contundencia se expresaba el Tribunal Supremo en su reciente Sentencia de fecha 28 de septiembre de 2007. En esta sentencia, el TS confirma la condena impuesta por quebrantamiento de una pena en un supuesto en que la mujer había consentido reanudar la convivencia y en ella parece querer desenredar la confusión creada con la Sentencia de 2005 al afirmar que «... una cosa es el incumplimiento de una medida de seguridad que, en principio, sólo puede aplicarse a petición de parte y cuyo cese incluso podría acordarse si ésta lo solicitase al Juez, que además tiene por objeto, obviamente, una finalidad meramente preventiva, y otra muy distinta aquella situación en la que, aun contando con la aceptación de la protegida, se quebranta no una medida de seguridad sino una pena ya impuesta cuyo cumplimiento no es disponible por nadie, ni aun tan siquiera por la propia víctima, cuando además se propicia con ese incumplimiento la comisión de hechos tan graves como los aquí enjuiciados...».

Este cambio jurisprudencial ha sido consolidado por el Acuerdo del Pleno no Jurisdiccional de la Sala Segunda del Tribunal Supremo de fecha 25 de noviembre de 2008, que recoge expresamente que el consentimiento de la mujer no excluye la punibilidad a efectos del art. $468 \mathrm{CP}$, lo cual será aplicable tanto si hay condena como si hay medida cautelar adoptada judicialmente. Este criterio viene a corroborar la postura mantenida por la Fiscalía General del Estado en el sentido de que la medida cautelar es indisponible por la víctima, la cual, si pretende dejar sin efecto su protección, deberá en todo caso realizar alguna actividad ante el juzgado manifestando su voluntad de que la protección quede sin efecto y explicando los motivos para que por el juez y el fiscal puedan valorar la oportunidad de que se mantenga o se deje sin efecto la medida cautelar. El problema puede plantearse cuando se constata que aún existe un riesgo objetivo para la víctima y que su voluntad de retirar la medida no está mediatizada ni condicionada.

La Sentencia del Tribunal Supremo de 29 de enero de 2009 viene a confirmar el Acuerdo del Pleno de 25 de noviembre de 2008 
en el sentido de considerar que en el delito de quebrantamiento de medida cautelar o pena es irrelevante el consentimiento de la víctima, todo ello de acuerdo con la «idea clave de la irrelevancia en el derecho penal del perdón de la persona ofendida por la infracción criminal, principio que sólo tiene su excepción en los llamados delitos privados, que es cuando expresamente la ley penal así lo prevé».

Esta resolución plantea el siguiente conflicto: considerar que si se opta por el mantenimiento a todo trance de la efectividad de la medida habrá que concluir que, si la mujer consiente en la convivencia, cabría considerarla coautora por cooperación necesaria al menos por inducción, ya que su voluntad tendría efectos relevantes cara al delito de quebrantamiento de medida del artículo 468 del Código Penal.

En estos casos, el primer Seminario de Fiscales Delegados de Violencia de Género celebrado en Madrid en noviembre de 2005 acordó, en una de sus conclusiones, que «Cuando el quebrantamiento se haya producido con el consentimiento de la víctima, no se procederá por el Fiscal a interesar la deducción de testimonio contra ésta por el delito del art. 468 del CP ni como autora por inducción ni por cooperación necesaria, al entender que tal conducta no es subsumible en los apartados a y b del art. $28.2 \mathrm{del} C \mathrm{P}_{»^{13}}$.

La STS de 8 de junio de 2009 resuelve un recurso de casación interpuesto por el Ministerio Fiscal ya que el Tribunal de Instancia, siguiendo la tesis mantenida por la STS de 26 de septiembre de 2005, entendió que "en la actualidad es atípica la conducta infractora de una medida cautelar de prohibición de aproximación y comunicación cuando se ha reanudado voluntariamente la relación entre el obligado por la medida cautelar y la persona protegida por la misma, puesto que en este caso desaparece la necesidad de la medida cautelar». Frente a esta tesis el Ministerio Fiscal cita la doctrina mantenida en la STS de 19 de enero de 2007, según la cual «la existencia del delito de quebrantamiento, aunque la mujer haya permitido la entrada de su pareja en el domicilio, manteniendo que la vigencia del bien jurídico protegido en el delito de quebrantamiento de condena no queda enervada o empañada por el consentimiento de la mujer, ya que es el principio de autoridad el que se ofende con el delito de quebrantamiento de medida».

Entendemos que esta duplicidad de posturas doctrinales entre el Tribunal de Instancia, que acoge la doctrina de la STS de 26 de sep-

\footnotetext{
13 Seminario de Fiscales Delegados de Violencia de género, Madrid, noviembre de 2005. Conclusiones.

VARGAS, A.: loc. cit., p. 2.
} 
El CONSENTIMIENTO DE LA VÍctima DE LA VIOLENCIA DE GÉNERO...

tiembre de 2005 y la del Ministerio Fiscal y otros Tribunales, que acogen la doctrina mantenida en la STS de 19 de enero de 2007 y, en definitiva la postura posterior del TS, es debida a una confusión doctrinal propinada por el cambio de doctrina del TS. Un cambio realizado sin más y sin justificar la modificación realizada.

En el recurso de casación, el TS simplemente hace referencia a que "frente a la anterior posición jurisprudencial, se ha de decir que, como se pone de manifiesto en la STS de 19 de enero de 2007, "el consentimiento de la víctima protegida por la condena penal no puede eliminar la antijuricidad del hecho». ¿Es acaso que, según la postura anterior que otorgaba relevancia al consentimiento de la víctima y excluía la existencia del delito de quebrantamiento de condena y de medida cautelar, sí que quedaba excluida la antijuricidad del hecho? Añade el TS que «la sanción penal que impone el alejamiento de determinadas personas como consecuencia de la conducta de agresión o de amenaza por parte de una de ellas contra la otra, o de la comisión de alguno de los delitos especialmente previstos en la ley (art. 57 y $48 \mathrm{CP}$ ), en cuanto constituye una pena impuesta por la autoridad judicial, que lógicamente obliga a su cumplimiento (art. 988 y 990 LECrim.), salvo resolución judicial legalmente fundada o concesión de indulto, en ningún caso puede quedar al arbitrio de los particulares afectados» (STS 30 de marzo de 2009).

En esta sentencia, el TS deja entrever la posibilidad de que una resolución judicial fundada en derecho pueda poner fin a una medida cautelar de alejamiento, dando así relevancia al consentimiento de la mujer expresado fehacientemente en este sentido.

\section{CONCLUSIONES}

Entendemos que en el tratamiento de esta problemática debe distinguirse claramente entre la relevancia del consentimiento de la mujer, en relación a una medida cautelar de alejamiento, y la irrelevancia del consentimiento de la mujer, en relación a una pena de alejamiento impuesta en sentencia. En este sentido, entendemos particularmente significativo el voto particular formulado en la sentencia recaída el 29 de enero de 2009. Los magistrados parten de la distinción entre el quebrantamiento de condena y el de medida cautelar de protección, señalando que se trata de problemas diferentes. Parten de la irrelevancia del consentimiento de las penas privativas de derechos, previstas en el artículo $48 \mathrm{CP}$, en el sentido de entender que el cumplimiento de las penas no puede quedar al arbitrio de la voluntad de 
un sujeto privado, en la medida que no se trata de un interés individual, poniendo en duda el caràcter general de la solución adoptada por la sentencia de la irrelevancia absoluta del consentimiento de la víctima, siendo preciso distinguir entre el quebrantamiento de condena y el de una medida cautelar de protección, sin que quepa plantear el problema y su solución de forma unitaria. Sí debe darse relevancia al consentimiento de la mujer cuando estamos ante una medida cautelar, teniendo en todo caso en cuenta las condiciones en que éste fue dado, ya que si en el proceso se hubiera comprobado circunstancias reductoras de la capacidad de la víctima para consentir - consentimiento viciado- (lo que no deja de ser posible en los supuestos de malos tratos habituales), se aplicarían las reglas que invalidan el consentimiento. Se parte de la consideración que una persona adulta que quiere reanudar una relación matrimonial no puede estar indirectamente limitada, contra su voluntad, por medidas cautelares de protección que estima innecesarias, puesto que ello sería incompatible con el derecho fundamental al libre desarrollo de la personalidad.

Entendemos que en los casos de consentimiento válido - no viciado- sería posible, en los delitos de quebrantamiento de medida cautelar, considerar dicho consentimiento como una causa de justificación. Esta solución intermedia es la que nos parece más ajustada a derecho y acorde con el principio de oportunidad y con el derecho constitucional al libre desarrollo de la personalidad del artículo $10 \mathrm{CE}$, pues haría coherente el cambio de jurisprudencia en esta materia.

Consideramos necesario valorar la posible modificación del tan discutido art. 57.2 CP, sustituyendo el efecto automático de su imposición por la ponderación en cada caso concreto de las circunstancias que concurren para imponerla o no, y considerando, entre otros factores, la gravedad del hecho, la valoración de la situación objetiva de riesgo de la víctima y, sobre todo, la valoración del riesgo. Con todo ello, trataremos de asegurar la prevención de estos hechos a través de los recursos e instrumentos que, sin duda, dispone nuestro ordenamiento jurídico.

\section{BIBLIOGRAFÍA}

AUTO de 29 de junio de 2005 del Juzgado de lo Penal n. ${ }^{\circ} 20$ de Madrid. Cuestión de inconstitucionalidad del art. 57.2 del CP ante el Tribunal Constitucional. 
CEREZO MIR, J.: Curso de Derecho Penal Español, Parte General. Tomo II, sexta edición. Ed. Tecnos; Madrid, 2004.

CIRCULAR de la Fiscalía General del Estado 2/2004.

JIMÉNEZ DÍAZ, M. J.: "Algunas reflexiones sobre el quebrantamiento inducido o consentido", en La Ley Integral: un estudio multidisciplinar (M. ${ }^{a}$ José Jiménez Díaz, coordinadora). Ed. Dykinson; Madrid, 2009.

MIR PUIG, S.: Derecho Penal, Parte General. Séptima edición. Ed. Reppertor; Barcelona, 2004.

MUÑOZ CONDE, F. y GARCÍA ARAN, M.: Derecho Penal. Parte general; sexta edición. Ed. Tirant lo Blanc, Valencia, 2004.

MUÑOZ CONDE, F.: Derecho Penal. Parte especial. Decimoséptima edición. Ed. Tirant lo Blanc, Valencia, 2009.

SEMINARIO de Fiscales Delegados de Violencia de género, Madrid, noviembre de 2005. Conclusiones.

SERRANO GÓMEZ, A. Y SERRANO MAILlO, A.: Derecho Penal. Parte especial. Treceava edición. Ed. Dykinson, Madrid, 2008.

SILVA SÁNCHEZ, J. M. (director) y RAGUÉS I VALLÉS, R. (coordinador): Lecciones de Derecho Penal. Parte especial. Segunda edición. Ed. Atelier, barcelona, 2009.

SUÁREZ LÓPEZ, J. M.: El delito de autoquebrantamiento de condena en el Código Penal español. Ed. Comares, 2000.

VARGAS, A.: «El llamado quebrantamiento consentido y los nuevos instrumentos de valoración del riesgo», El Derecho, Revista de Jurisprudencia, Año III-Núm. 1, diciembre 2007. 
